\title{
A Critical Evaluation of Training within the South African National Public Works Programme
}

\author{
ANNA MCCORD \\ Southern Africa Labour and Development Research Unit (SALDRU), \\ University of Cape Town, South Africa
}

\begin{abstract}
This article explores the ability of the training and work experience offered under public works programmes to promote employment in South Africa. Public works are a key component of South African labour market policy and are ascribed considerable potential in terms of addressing the core challenge of unemployment. However, despite this policy prominence, the labour market impact of the training component of such programmes has not been studied systematically in South Africa, from either a theoretical or empirical basis, and this article attempts to provide an initial critique of the programme from both perspectives. This article outlines the unemployment situation in South Africa and the training component of the government's national public works programme, the Expanded Public Works Programme (EPWP), which was developed to enhance workers' skills and labour market exposure, and thereby improve their subsequent employment performance. Theoretical and empirical arguments are used to develop a critique of the training component of the programme, and the article concludes by arguing that, as currently conceptualised, the national public works programme is unlikely to have a significant impact on skills development or unemployment, due the structural nature of unemployment, excess supply of low and unskilled labour, and the high skills growth strategy adopted by government.
\end{abstract}

\section{Background}

Poverty and unemployment are the two key economic challenges in contemporary South Africa. Unemployment has been rising for 30 years, reaching a plateau in 2004 at extremely high levels, standing at $28 \%$ in March 2004 by the narrow definition, and $41 \%$ by the broad definition 
(Statistics South Africa, 2004). Structural changes in the economy, arising from integration into the global market, increased mechanisation and declines in labour absorbing sectors, such as mining and agriculture, have lead to rising unemployment and a significant decline in the demand for unskilled labour (Bhorat \& Hodge, 1999). Even under a positive growth scenario, broad unemployment among the semi-skilled and unskilled is unlikely to fall below $30 \%$ in the medium term (Lewis, 2001, p. 55). Unemployment is structural and will not be significantly reduced in the coming decades without major state intervention, given South Africa's current high skills growth strategy.

Of a total population of 45 million, some 20 million live below the poverty line [1] (Meth, 2004, p. 69). These poverty levels are closely correlated with unemployment, with the poorest experiencing unemployment rates of more than 70\% (Samson et al, 2003), while most households in the bottom four income deciles have no members in employment. Given the strong correlation between wage income and poverty in South Africa, responding to unemployment is clearly a key policy challenge.

\section{South African Labour Market Policy and the National Public Works Programme}

In terms of labour market policy choice, the fundamental question is whether the problem is characterised as a demand or supply side problem, with the respective policy choices being deliberate stimulation of large scale employment, for example, through public employment schemes or interventions to address supply side issues, by improving the quality of labour available.

In South Africa the promotion of GDP growth is envisaged as the primary instrument to increase employment, in the context of a high skills growth strategy (see Kraak in the introductory chapter to this Special Edition).[2] In addition, there are a small number of skills training interventions, together with an emphasis on the development of Small, Micro and Medium Enterprises (SMMEs) and the promotion of Black Economic Empowerment (BEE), to redress the economic and labour market segmentation arising from over a century of racialised economic and labour market policies.

Beside modest increases in government expenditure in infrastructure provision and reduced bottom-end labour market regulation, both of which are intended to stimulate labour demand (Growth and Development Summit, 2003; African National Congress [ANC], 2005) the main demand side intervention accessible to the unskilled unemployed is the national public works programme. The Expanded Public Works Programme (EPWP), which was launched in 2004, aims to provide between 100,000 and 200,000 short-term jobs each year 
over a 5-year period, and to provide skills training and work experience. This programme and the labour market assumptions that support it are critically examined in this article.

\section{The Economic Analysis Underlying the EPWP}

The EPWP is fundamentally a supply side intervention, since the direct labour market impact of the EPWP in terms of the number of jobs 'created' is extremely limited, and the average duration of employment on the programme is only 4 months.[3] The EPWP is premised on the assumption that the acquisition of skills and work place experience will improve labour market performance. This implies that unemployment is at least in part 'frictional' [4], and corresponds strongly with analysis underlying active labour market policies in developed countries, which leads to the selection of interventions based around skills development. Whether such an analysis and policy response is appropriate in the South African context of significantly higher levels of unemployment, which is primarily structural rather than frictional is open to question. This article questions whether this characterisation is correct or even useful.

Bhorat has outlined the key economic considerations that underpin this assumption that supply side interventions promoting skills acquisition represent a viable means for integration into the labour force. He argues that:

given the unevenness of the economy's growth generation both in terms of sectoral expansion and skills requirements - a fair degree of intervention is clearly required on the labour supply side. Put differently, the simultaneous existence of a skilled labour shortage and unskilled labour surplus, point to the importance of adhering to a policy framework that emphasizes both the need to kick-start economic growth as well as ensuring that the characteristics of the suppliers of labour match those in demand by growing sectors. (Bhorat, 2004)

This analysis is reflected in thinking underlying the EPWP:

Two fundamental strategies underpin the government's approach to reducing unemployment. Firstly, to increase economic growth so that the number of net new jobs being created starts to exceed the number of new entrants into the labour market, and secondly to improve the education system such that the workforce is able to take up the largely skilled work opportunities which economic growth will generate. Short to medium-term strategies have been put in place to contribute towards these strategies. The EPWP forms one of government's 
short to medium-term strategies. (EPWP, 2005, emphasis

added)

The critical question however, is whether improving the supply side characteristics of the unskilled mass of the unemployed through EPWP participation and training will enable them to take up the 'largely skilled work opportunities which economic growth will generate'? This is one of the key questions in the current South African labour market policy discourse: Are supply side interventions an appropriate and significant response to the structural unemployment that characterises the South African labour market? When specifically applied to the EPWP the question becomes: Do the experience and training benefits of participation in public works programmes enable labour to take up the skilled work opportunities that economic growth will generate?

This article will first outline the aspirations and content of the EPWP. Then it will examine the nature of demand for skilled labour being created within the current South African growth trajectory, and thereafter compare this with the nature of the skills offered in the public works programme. The article will also look at the empirical evidence offered by public works programme studies, to see if this corroborates the conclusions of the more theoretical analysis.

\section{How Will the EPWP Impact on Employment?}

The EPWP is designed to 'provide poverty and income relief though temporary work for the unemployed to carry out socially useful activities', while at the same time equipping participants 'with a modicum of training and work experience, which should enhance their ability to earn a living in the future' (Growth and Development Summit Agreement, June 2003, cited on 'Welcome to the EPWP' website, Department of Public Works). The intention of improving labour market performance through EPWP participation is set out in more detail in the EPWP documentation:

The EPWP is a nation-wide programme covering all spheres of government and state-owned enterprises that aims to draw significant numbers of unemployed into productive work accompanied by training so that they increase their capacity to earn an income. ... either through the labour market or through entrepreneurial activity. (EPWP, 2005)

This represents a vision wherein the immediate benefit is temporary employment, and the medium term benefit is improved labour market performance, the holy grail of employment, for those who have passed through the EPWP process, entering as unskilled labour and exiting as labour possessing skills in demand in the economy, which will lead to employment in the first economy. The aspiration of the training included 
in the EPWP is to form a ladder from the second (periphery) to the first (core) economies, using the metaphor popular in the current labour market and poverty discourse in South Africa.[5]

The analysis underlying this approach is predicated on the assumption that supply-side interventions can have a significant impact on unemployment among the un/low-skilled, as assumed in the EPWP. The EPWP documentation recognises explicitly that without the skills development component, the impact of temporary public works employment would be of limited value:

job creation without skills development, upgrading and training, does not lend itself to sustainable employment and will have no long-term economic impact on the lives of the unemployed ... (EPWP, 2004 a or b??, citing the Growth and Development Summit, 2003)

This insight is important given the three key vectors through which EPWP employment has the potential to influence labour market performance - work experience, on the job training and formal training suggesting that labour market experience alone may not be sufficient for the programme to meet its policy objectives. Notwithstanding this caveat, labour market experience was accorded high importance in the EPWP design due to the high levels of youth unemployment in South Africa, and the high percentage of the unemployed who have never worked.

The idea at the heart of the EPWP strategy is that increased skills translate directly into improved labour market performance. Since the objective of the programme is increased employment, there seems to be a broad correspondence of problem and solution - add skills to unskilled labour and it will serve to meet the excess demand for skilled labour. Thus, workers will move from the periphery to the core of the labour market. The implicit assumption is that workers will metamorphosise from unskilled to skilled workers for whom there is unmet demand.

However, the analysis underlying this approach is shown to be problematic when the nature of the 'skills deficit' in South Africa is examined in more detail and the crude binary characterisation of skilled/unskilled labour is unpicked. The analysis informing the EPWP assumes that there is a one-on-one mapping of improved skills to improved labour market performance, implying that some incremental labour market benefit will accrue in line with incremental skills acquisition. However, it fails to recognise the size of the skills gap that must be bridged before increased employment opportunities will be accessible to workers. Detailed labour market analysis presented here suggests that the picture is more subtle than a simple incremental model suggests and that there is a key skills threshold workers must cross before their skills accumulation will have an impact on labour market performance. 
In South Africa, unmet labour demand is primarily for labour with intermediate and high skills, and there is no easily identifiable unmet labour demand for semi or low-skilled labour (Kraak, 2003), which most closely describes EPWP labour at the point of exit from public works employment. Hence, in order for the EPWP work experience and training to have a significant impact on employment performance, they would have to provide workers with intermediate level skills, for which there is significant unmet demand.[6] In order to test whether the training offered through the EPWP is sufficient to bring participants to this skills level, the nature of the training provided under the EPWP is examined in detail below.

In the EPWP, on the job training is provided by individual contractors in order to ensure workers have the skills required to perform their tasks (such as basic construction activities), while formal training is provided under the auspices of the Department of Labour for 2 days for every 20 worked by public works employees. Given that the mean period of employment for most EPWP employees is 4 months, the average duration of the formal training component of the EPWP is only 8 days.

The assumption is, that the level of skills accruing to workers through up to 8 days training over some months on the job training, will be sufficient to move them out of the low or unskilled segment of the labour force, and into the intermediate skilled segment. Analysing the likelihood of this mobility from one sector to another is critical, as unless this occurs, it is unlikely that participation in the EPWP programme will have any positive impact on labour market performance, as there is no or minimal unmet demand for low and unskilled labour. This is the question that will be considered below.

\section{How Will Training Be Delivered through the EPWP?}

The EPWP comprises four sectors: infrastructure, environment, social and economic. The organogramme for the EPWP and the roles and responsibilities of the different institutions involved is outlined in Figure 1.

According to the EPWP plan, the infrastructure sector will dominate the other sectors, providing up to 900,000 of the proposed 1.3 million work opportunities, compared with 200,000 in the environmental, 150,000 in the social and only 12,000 in the economic sectors.[7]

In each sector training is recognised as central, and this is clearly articulated in the EPWP Social Sector Plan:

One way of viewing the EPWP is as a bridge between unemployment and employment during which participants are equipped with skills and experience. As such the EPWP is exempt from much of the current labour legislation. In return 
for this exemption the programme is obliged to provide a higher level of training than participants would normally get in any other place of work. Training is therefore the backbone of the EPWP Code of Good Practice. Developing the capacity to deliver on this commitment is critical to the success of the programme. (EPWP Social Sector Plan (EPWP, 2004a, p. 28, emphasis added)

In the South African context, the Skills Development Act requires that a skills programme must be occupationally based, provide a credit towards a qualification registered in terms of the National Qualifications Framework (NQF), address identified skills needs, and make use of accredited training providers. The Department of Labour National Skills Fund and the SETAs have developed EPWP training accordingly, with the Department of Labour coordinating the training and skills development components of the programme.[8]

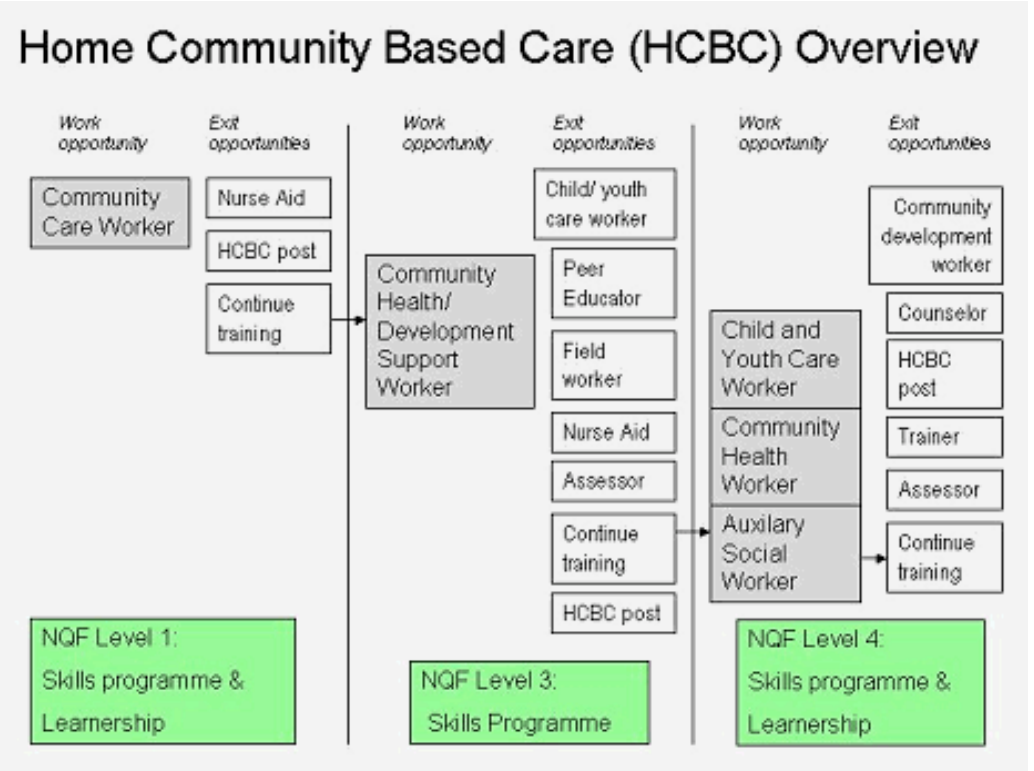

Figure 1. Employment and Training in the HCBC Programme.

Source: http://www.epwp.gov.za/

In recognition of the unskilled nature of most of the work opportunities offered and, hence, the limited value of job experience per se in promoting skills development, the Social Sector indicated that 'all of these work opportunities will be combined with training or education or skills development, with the aim of increasing the ability of people to earn an income once they leave the programme' (EPWP, 2004a). 'Learnerships' 
are the main vehicle of formal training offered under the EPWP, providing workers with a combination of on-the-job experience, a stipend and training, which leads to $\mathrm{NQF}$ qualifications and 'possible longer-term income opportunities' (EPWP website).[9] However, such learnerships are only accessible for a small minority of EPWP participants, and for the majority of the unskilled workers, the training options are far more limited, as is indicated in Table I.

\begin{tabular}{lcc}
\hline Sector & $\begin{array}{c}\text { Total temporary employment } \\
\text { opportunities anticipated } \\
\text { during the 5 years of the } \\
\text { EPWP (approximate) }\end{array}$ & $\begin{array}{c}\text { Total learnerships } \\
\text { anticipated during the 5 } \\
\text { years of the EPWP } \\
\text { (approximate) }\end{array}$ \\
\hline Infrastructure & 900,000 & 500 \\
Environment & 200,000 & 400 \\
Social - HCBC & 122,240 & 17,400 \\
Social - ECD & $57,800^{*}$ & 19,800 \\
Economic & 12,000 & 3,000 \\
Total & $1,292,040$ & 41,100 \\
\hline
\end{tabular}

*Estimate based on outline in EPWP Social Sector Plan (EPWP 2004a).

Table I. Total employment and learnership estimates in the EPWP.

This clearly indicates that the numbers of EPWP employees for whom formal 'learnerships' leading to NQF qualifications will be attained is extremely limited. For most, the training component of the EPWP will not lead to the acquisition of qualifications, which would pull them into a higher skills bracket. The EPWP has a focus on training for contractors managing the workers, rather than the mass of the workers themselves. This is significantly different from the training activities implied in the EPWP documentation, which refers to "training and learnerships for all beneficiaries for a minimum of two days per month worked " (EPWP, 2004b). Clearly, training is for all, but not learnerships. At this point the critical question becomes, what is the nature of the training offered to workers in the 2 days allocated for each month worked and what is its value in terms of success in the labour market? The training proposed in each sector is explored below.

\section{Infrastructure Sector}

In the infrastructure sector, the EPWP focuses on increasing the labour intensity of government-funded infrastructure projects, with the objective of creating 900,000 temporary work opportunities.

Two-hundred-and-fifty 'emerging contractors' [10] will participate in Construction Education and Training Authority (CETA) learnerships during the 5-year period of the EPWP [11], gaining skills in labourintensive infrastructure construction and preferential access to 
finance.[12] Whereas for workers, on the job training will be complemented by an average of 8 days 'livelihoods training', on the basis of 2 days training for each month worked. According to the programme rhetoric this training is intended to equip them 'with skills which will enhance their ability to obtain an income after the projects have been completed' (EPWP, 2005). However, critically, the EPWP recognises that:

This is not sufficient to train unskilled labourers to become

artisans. It has therefore been agreed with the Department of Labour to create a generic 10 to 14 day training course that will consist of accredited unit standards on: general life skills, awareness of HIV and AIDS, and labour markets and the world of work. (EPWP, undated, p. 8)

The message is clear; the training given to the mass or workers participating in the EPWP - and specifically in the infrastructure sector will not be sufficient for workers to acquire the skills in demand in the South African labour market, or more specifically to 'become artisans'.[13] This is not unexpected given the traditional 5 years duration of the artisanal training or apprenticeship in South Africa. However, the fact that this needs to be stated formally is due to the unrealistic expectations aroused elsewhere in the EPWP documentation and associated policy rhetoric, which asserts that workers will receive training, while participating in the programme such that they will be enabled to take up the unfilled employment opportunities existing in the South African economy, despite the fact that these opportunities are almost exclusively for labour with intermediate or high skills. In the place of vocational training or skills upgrading, which could potentially improve their labour market prospects, workers will receive only informal on-the-job training, life skills training and labour market information through the EPWP. While these inputs may be of value in terms of aspects of workers' lives, it is not clear that this training will have a significant beneficial impact on labour market performance, particularly given the main constraint to employment is net lack of demand for low-skilled labour.

If EPWP workers were successful in accessing employment after their EPWP training, this would represent the substitution of one set of low/skilled workers by another, rather than a net increase in employment. However, even this substitution impact is unlikely, since workers engaging in infrastructure programmes perceived lack of jobs, skills and funds for job search as the main constraints to improved labour market performance, even after EPWP experience and training (see, for example, McCord, 2004; Ndoto \& Macun, 2005). In the light of this, it is not clear that the training will contribute to the goal of increasing workers' 'capacity to earn an income once they leave the programme' (Mbeki, quoted in This Day, 12 November 2003). 


\section{Environment Sector}

The environment sector comprises the Departments of Environmental Affairs and Tourism (DEAT), Water Affairs and Forestry (DWAF), Arts and Culture, and Agriculture. In this sector, the aim is to create 200,000 temporary work opportunities, and 400 sustainable SMMEs. The intended exit strategy is for workers to be placed in permanent jobs in forestry, commercial fisheries, tourism and horticulture. However, in recognition of the lack of employment demand in these sectors, at least two of the main programmes in this sector, 'Working for Wetlands' and 'Working for Water', which have been operational for several years already, have unofficially suspended their exit strategies.[14] In other words, they have retained workers for multiple years, rather than disgorging them back into unemployment once the original term of their temporary period of public works employment is completed (see, for example, Ndoto \& Macun, 2005).

\section{Social Sector}

The Social Sector is the most ambitious, but to date, least developed component of the EPWP. It has the most significant programme to develop intermediate and high level skills. The social sector is comprised of the Departments of Social Development, Health and Education and the social component of the EPWP has two components, Home Community Based Care (HCBC) and Early Childhood Development (ECD).[15]

It is planned for the HCBC programme to be implemented in collaboration with the Health and Welfare Sector Education Authority (HWSETA), and to offer temporary work opportunities for 120,000 workers, 17,400 of whom will participate in learnerships offering low and intermediate level skills. The ECD programme will skill 20,000 workers, with the dual objective of increasing workers' capacity to generate an income, while also improving early childhood development. This component will be implemented in collaboration with the Education, Training and Development Practice Sector Education Training Authority (ETDP SETA). For detailed plans of the training anticipated in the HCBC programme (see Figure 2).

\section{Economic Sector}

The economic sector plan focuses on stimulating micro-enterprise through a 'venture learnership' project, with 3000 learners participating in SETA-funded learnerships and being assisted to establish SMMEs, which will be allocated public sector 'learning contracts'. Workers will graduate from learnerships with the technical knowledge required to tender for public sector projects and run businesses, while also gaining a 
formal NQF qualification, experience and a credit record. The EPWP estimates that each SMME will employ up to three people, bringing the total number of temporary employment opportunities created up to 12,000 .

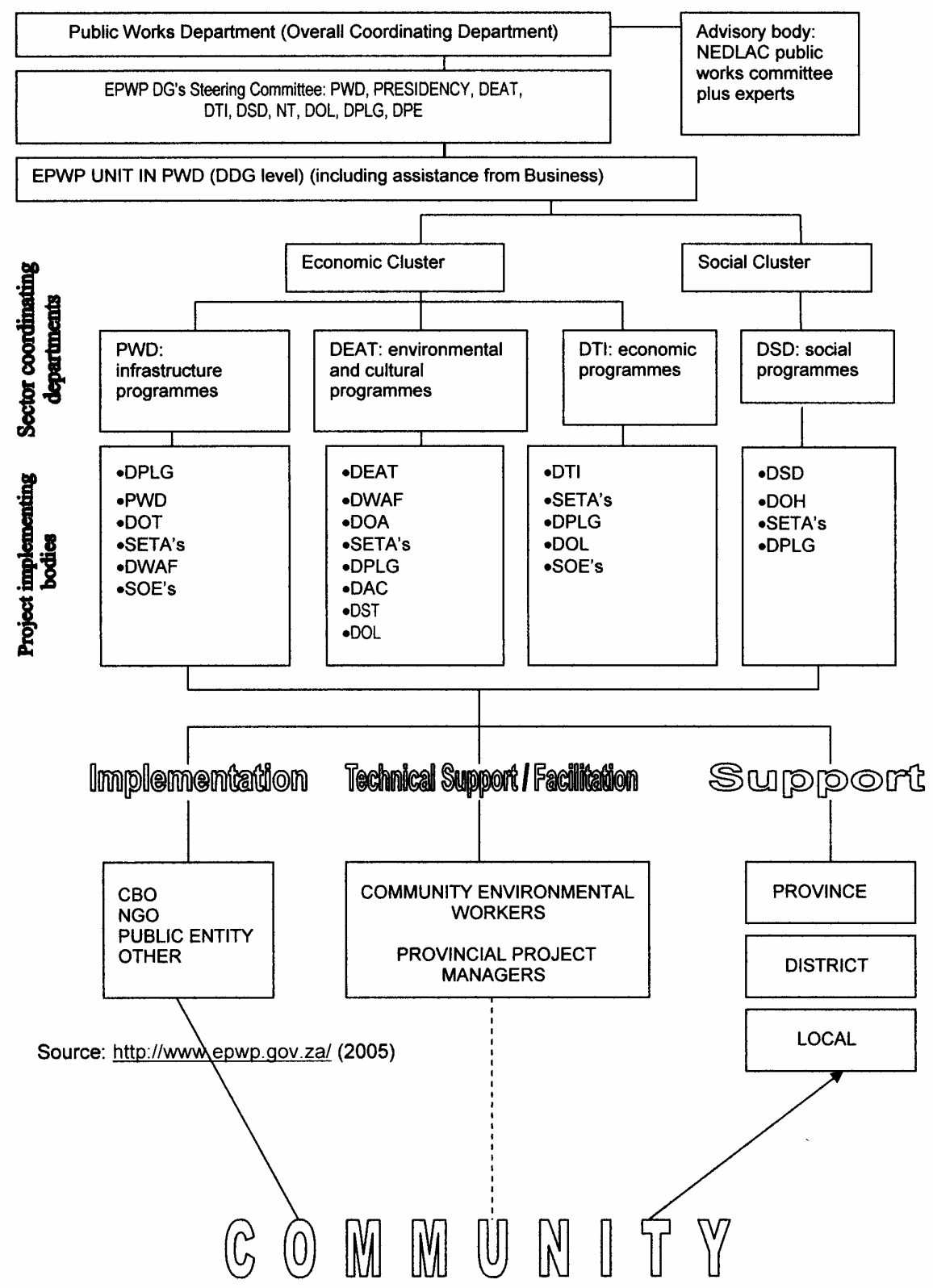

Figure 2. PWP Organogramme. 


\section{Sectoral Conclusions}

Each sector offers quite different forms of employment and training. The infrastructure sector provides almost exclusively short-term employment, with extremely limited formal training opportunities. By comparison, the social sector, which is less well developed conceptually and in terms of implementation, is attempting to pioneer service provision as a form of social public good, in place of the more conventional physical public goods in the form of infrastructure, which are usually associated with public works programmes. In the social sector plan a greater proportion of the workers are likely to have access to significant formal training than in the other sectors.

\section{Institutional and Analytical Critique}

An initial critique of the assumptions underlying these programmes in relation to its labour market ambitions is outlined below.

\section{The Limited Number of Learnerships}

The number of learnerships included in the EPWP is very low, given the size of the programme. On the basis of the indicative figures in Table I, it can be assumed that only $3 \%$ of those employed in the EPWP may expect any kind of formal skills based training, as formal skills training is only offered through the learnership system.

\section{Limited Training for the Short-Term Employed}

With training opportunities limited to 2 days for every 20 worked, for most participants in the EPWP, the average length of training will be 6-8 days [16], which as the EPWP concedes, is too short a period for vocational training to move workers from the unskilled to the intermediate segment of the labour market. For these workers the only vocational training or skills that will be acquired will be through on-thejob training for work that is primarily low or unskilled. This is not likely to make a significant impact on the skills level of EPWP participants. The only formal training these workers will receive will be life-skills related, rather than directly vocational.

\section{Capacity Constraints on the Implementation of Training}

It is not apparent that the Department of Labour and training providers have the capacity to deliver the 'efficient, to scale and quality training' (EPWP, 2004a), which is core to the success of the programme.[17] 
Whether the significant numbers of training providers required to support more than a million workers over 5 years are readily available and able to provide quality training remains an open question, given the massive expansion of training activity implied by the proposed EPWP training schedule.

Furthermore, programme development and implementation responsibilities have been added to the workload of participating line ministries, at central, provincial and district levels, where overload and lack of managerial and administrative capacity have already been noted. These capacity constraints have potentially negative implications for the EPWP, particularly the development and implementation of the ambitious social sector component of the programme.

\section{Lack of Demand for Low and Unskilled Labour}

Notwithstanding these implementational constraints, the most significant critique of the programme relates to the reality of market demand. As recognised in the EPWP Social Protection Plan:

The key challenge here is to translate work opportunities into long-term livelihoods. The premise of the programme is that skilling on the job will assist workers to find more permanent employment. Whilst every effort has been made to carefully consider exit opportunities, few of these are available in the private sector and therefore, it is highly likely that the primary financial burden will remain with government. (EPWP, 2004a)

This note of realism represents a key insight into the core problem with the EPWP training strategy. The programme is based on the assumption of a generalised unmet demand for workers, even for those with the low level skills that may be acquired through EPWP participation. However, there are no labour market indications that such low skill jobs exist. Nor can we assume that the majority of EPWP graduates are or will be, in any significant way, distinguishable from non-EPWP participants in terms of their acquired skills. In the light of this over-valuation of the extremely limited skills transferred through the EPWP, it is unlikely that EPWP participation will assist workers to move from the second (periphery) to the first (core) economy.

\section{Empirical Evidence}

Having reviewed the labour market situation and the lack of fit between the skills level of labour exiting public works programmes and the skills profile of labour for which unmet demand persists, we now examine recent micro-economic data, to see if research findings corroborate the argument set out above. The data is drawn from quantitative and 
qualitative survey work carried out with public works employees working on programmes that are part of the EPWP, by McCord (2004) and Ndoto \& Macun (2005).[18] Both studies explore the labour market performance and perceptions of public works participants.

\section{The Labour Market Status of PWP Participants}

In both studies, limited baseline labour market data was recorded on participants, rendering time series analysis of the labour market impact of the programme of public works interventions problematic. Hence, programme impact had to be inferred primarily from recall questions and focus group discussion, and while these techniques are not optimal, they nevertheless offer significant insights into the labour market impact of the training and experiential components of EPWP public works programmes.

\section{Perceptions of Training and its Value}

In both studies, workers were asked how they perceived the value of the training and work experience gained through participation in the public works programmes, in terms of their labour market prospects. In both programmes, workers overwhelmingly stated that the training offered in the programmes had little impact on their actual or anticipated labour market performance. Ndoto \& Macun argued that 'It would appear that the programme's intervention has not made significant difference with regards to skills provision' $(2005$, p. 31$)$ and concluded that:

the programme improved people's livelihoods, in terms of income [during the period of employment], and removed some constraints to accessing education and improved nutrition ... The situation was however different with regard to skills. We found that although the programme provides some technical (e.g., construction skills) and life skills (e.g., First Aid, Health and Safety, etc.), they did not feel outright that these skills were likely to improve their employment prospects. (Ndoto \& Macun, 2005, p. 32)

In the McCord study, many workers even expressed uncertainty as to whether they had received training or not, with only 38\% of 'Gundo Lashu' workers reporting that they had been 'trained' in any way (formal or informal), despite the fact that all were given at least 'on-the-job' skills training in line with EPWP standards (McCord, 2004, p. 74). Ndoto \& Macun attribute this failure among workers to value training in part to the fact that workers were 'not presented with any form of certification as a form of proof that they were indeed trained, especially on technical skills' 
(2005, p. 34) and the fact that the training was 'on the job', rather than classroom based.

Given the importance of perception and confidence in labour market performance, Ndoto \& Macun conclude that:

The beneficiaries' failure to acknowledge the skills ... would seem to suggest that more work needs to be done along the lines of ensuring that the beneficiaries recognise the training they are provided with if the programme's impact is to be sustainable. Failure to do so would render the training provided to the workers worthless and taken for granted as illustrated above. (Ndoto \& Macun, 2005, p. 33)

\section{Training and Employment Performance}

Interestingly, only $6 \%$ of workers who had completed employment in the Gundo Lashu programme reported that the training they had received had assisted them in finding work (McCord, 2004, p. 63). The primary explanation given for this by workers was overwhelmingly the lack of employment opportunities (this was the primary reason put forward by $61 \%$ of respondents). McCord argues that this represents a realistic analysis of their labour market prospects on the part of the workers, given the high levels of unemployment prevalent in the area of programme implementation (McCord, 2004).[19]

Survey findings from the 'Gundo Lashu' programme confirmed the appropriateness of the pessimism expressed by workers about the prospects of finding employment after participation in public works, with a broad unemployment level of $80 \%$ reported among former public works employees. The absence of more detailed information on the labour market characteristics of public works employees, in comparison to the broader population and their prior labour market performance makes it difficult to draw conclusive findings from these unemployment levels. However, they indicate clearly that post-programme labour market performance remains extremely poor in the case of this group of workers who have passed through the EPWP training and experiential 'package'. The inference which can be drawn from this is that participation in such a programme may not necessarily lead to significantly enhanced labour market attachment.[20] As McCord concludes:

The extremely high prevailing unemployment level among former PWP workers fundamentally challenges the assumption that PWP participation has a significant beneficial impact in terms of subsequent employment performance. (McCord, 2004, p. 33)

These findings are consistent with Kraak's analysis that there is not unmet demand for workers emerging from public works programmes with 
skills levels that remain low (Kraak, 2003). The consequence is that upon emerging from public works employment workers may well return to their labour market status quo ante, as attested by a worker from Bushbuckridge currently employed in the 'Working for Wetlands' programme:

[Working for] Wetlands is boosting us, so if this contract gets terminated, it means that we are going to have to go back where we were ... because there will not be any income. (cited in Ndoto \& Macun, 2005, p. 35)

Workers anticipated that upon exiting the programme, they would return to a reliance on a combination of horizontal social support (parents and family) and engagement in the secondary segment of the economy for their survival:

'I'll sell some sweets' and 'I'll open a small market at home, sweets, bread and fish ... I'll sell these things, life goes on' (Ndoto \& Macun, 2005, p. 35)

Rather than moving up the hierarchy of the labour market, once they have their 'foot on the employment ladder' (Department of Public Works, 2004), evidence from 'Gundo Lashu' and 'Working for Wetlands' suggests that in fact workers return to the same labour market 'rung' from whence they came into the programme.

\section{Training and Informal Employment}

It would be a mistake, however, only to evaluate the impact of public works in terms of subsequent engagement in the formal sector or the primary segment of the labour market. Increased participation in the second or informal segment of the labour market would also represent a benefit for workers. The impact of public works participation on participation in this segment was examined by McCord, who found that only $12 \%$ of 'Gundo Lashu' participants reported increases in microeconomic activity as a result of public works employment, citing the main constraint overwhelmingly as lack of access to capital and/or credit (83\%; McCord, 2004, p. 64). The duration of employment and wage level associated with public works meant that levels of savings and accumulation in these programmes were low, and as a consequence the potential to accumulate the capital or material goods required to facilitate new or increased micro-enterprise was limited. 


\section{Why Might EPWP Participation not Improve Labour Market Performance?}

The main factor underlying the limited success of the EPWP programme to improve labour market performance is the limited demand for low and unskilled labour. This factor dominates all others, but nonetheless interesting training policy implications arise from the subordinate factors:

- lack of potential to accumulate the productive assets required to stimulate secondary labour market activity;

- training which is not perceived as valuable by recipients;

- failure to recognise the heterogeneity of the unemployed.

As currently designed, the EPWP offers primarily short-term employment opportunities and, hence, does not enable a sufficient accumulation of resources for workers to enter or expand activities in the secondary sector, moving up the value chain from local level production and sale of natural products, e.g. firewood, clay or reed products, to those requiring capital for material purchase or enabling transportation of products to more distant markets where greater profits may be realisable. In this way, public works employment is unlikely to stimulate significant sustained increases in micro-enterprise or survivalist activities, thereby failing to create additional 'employment' in the informal sector. Given the structural failure of the formal sector to provide employment opportunities to absorb public works 'graduates', this failure of public works to stimulate informal sector employment opportunities is problematic and needs to be considered. Strategies for addressing this could focus on promoting coordination with initiatives to stimulate accumulation through coordination with other development initiatives such as savings and access to micro-credit, the inclusion of microenterprise training (skills or business orientated) and the provision of materials or other physical assets to stimulate production and marketing.[21]

The work of both McCord and Ndoto \& Macun highlights the limited value ascribed to training by public works employees. The training offered is not seen as valuable or relevant in terms of promoting future labour market performance, and seems to have limited impact on labour market performance. There is a significant discrepancy between the training menu offered under the EPWP for regular labourers, with its focus on life skills and labour market information, and the skills and training cited by workers as of market value, such as driving lessons, security personnel training and cell phone service provision. While the work of Nattrass suggests that labour market information is important in terms of successful job search (Nattrass, 2000), and this intervention may reduce frictional unemployment to the limited extent that it exists in the 
South African labour market, there is little evidence to suggest that lifeskills training will have a significant impact on labour market performance.[22]

Even if the programme were successful in terms of increasing the employment of workers in existing public works programmes, through improved labour market information and the provision of skills certification, given the lack of excess demand for low skilled labour, this employment would be at the expense of other workers, leading to the substitution of one segment of low/unskilled labour by another, with a zero net social or labour market benefit. If skills were offered that focused on the promotion of employment in the 'second economy', promoting the creation of additional informal employment in the secondary segment of the labour market, then the economy would benefit from the expansion of overall employment, rather than from attempting to increase supply in an area where demand is seriously constrained. This issue is explored further in Devey et al (2003), who argue that existing government training schemes are not sufficiently oriented to the promotion of informal survivalist economic activity, and that the current structure of training does not beneficiate those engaged in the informal economy, but focuses too closely on the promotion of formal and first economy activities.

Finally, the training offered in the EPWP is not sensitive to the heterogeneity of the unemployed, and the profoundly different labour market options available to different segments of the labour force. A crude distinction was drawn by Bhorat (2001) between the young mobile unemployed, and older rural unemployed workers with limited education and mobility, whom he characterised as 'unemployable' in terms of existing demand in the formal sector, and for whom he argued formal skills training was not an appropriate policy response (Bhorat, 2001). Lee $\&$ Woolard (2002) took the analysis further, developing a typology of the unemployed, based on education, age, gender, work experience and urban/rural location. The conclusion of this work is that a offering a homogenous training product comprising life skills and labour market information to the low and unskilled unemployed is unlikely to meet the diverse labour market needs of the many different categories of the unemployed. It is critical to recognise the heterogeneity of the unemployed labour force and adapt policy responses accordingly. This is particularly important in relation to the training and skills development interventions offered within the EPWP.

\section{Conclusions}

According to the head of the EPWP, the 'Government's job creation programme [is] on track' (cited in BuaNews, Pretoria, March 10, 2005). He went on to say: 
EPWP is not a solution for poverty in South Africa, the main aim is to create job opportunities and improve the level of education and training.

However, having reviewed the labour market situation in South Africa, and the training inputs offered under the EPWP, it is fair to say that while participation in the EPWP may lead to improved levels of training for participants, this is unlikely to translate into improved labour market performance. While temporary job opportunities are being created and workers are receiving a modicum of education and training, this is unlikely to lead to a net increase in employment in South Africa, or significantly improve the labour market performance of participants. The formal training offered to the majority of workers is not skills orientated, on the job training tends to be low skilled, and work experience may at best lead to labour substitution, rather than increased employment, as a consequence of the lack of demand for low and unskilled labour. No skills shortage has been identified for the genre of low level skills acquired by workers through participation in most EPWP sectors [23], and given the high skills growth strategy adopted by the government, it is unlikely that demand for low and unskilled labour with the skills and experience acquired through participation in the EPWP will increase significantly in the short or medium term.

The analysis underlying the EPWP is predicated on the assumption that supply-side interventions can have a significant impact on poverty and unemployment among the low-skilled, an analysis which is problematic when the fundamental problem is the structure of the South African economy and the falling net demand for workers without at least intermediate skills. The EPWP offers a limited window for the unemployed or informally employed to access financial resources, skills and experience from the state. It offers a unique opportunity for the state and the unemployed to meet and for the state to intervene to promote the labour market performance of participants. It is critical that this opportunity be used optimally to advance these goals, and that the training component of the package is reconsidered, in line with the reality of the South African labour market. Unless this rethinking takes place, it is unlikely that the resources being expended on the EPWP will ensure that:

participants in the EPWP are able to translate the experience and either enabled to set up their own business/ service or become employed. (EPWP, 2004a)

To date, the limited evidence available suggests that participants in the EPWP are likely instead to return into the pool of the unemployed, from whence they came. 


\section{Correspondence}

Anna McCord, Public Works Research Project, SALDRU, Centre for Social Science Research, School of Economics, University of Cape Town, Private Bag, Rondebosch 7001, South Africa (amccord@iafrica.com).

\section{Notes}

[1] There is no official poverty line in South Africa. This figure of 20 million is derived using a poverty line developed by Statistics South Africa.

[2] For a critique of the selection of a high skills growth strategy in the context of South Africa, given the limited level of low skilled employment see Ashton (2004).

[3] For a full discussion of the direct labour market impact of public works interventions in South Africa (see McCord \& van Seventer, 2004).

[4] Frictional unemployment, which may be contrasted with structural unemployment, is caused when people move between jobs or when they are temporary unemployed due to the need to acquire the new skills required by a changing labour market. In the case of frictional unemployment, where there are unmet labour demands, a labour market intervention focused on the training required to provide the skills required in the changing economy will lead to a reduction in unemployment.

[5] See, for example, the speech given by the Minister of Labour on 27 November 2003, referring to the training component of one EPWP infrastructure programme:

The training programmes ... are not just instances of isolated interventions. They are part of a carefully considered Growth and Development strategy on the part of the ANC government - a strategy which has been carefully planned to created a ladder between the two worlds and ensure that those who suffer from poverty and unemployment have a real chance to climb that ladder and secure for themselves and their families a decent life with decent levels of support in the process.

[6] South Africa is currently experiencing particularly acute shortage of intermediate and high skilled labour in the construction sector, which is leading to the importation of artisanal skills from overseas (Brunjes, 2003).

[7] While the figure of one million jobs is widely used in the popular presentation of the EPWP, according to EPWP website the goal of the EPWP is 'to alleviate unemployment for $a$ minimum of one million people [...] in South Africa between 2004 and 2009' (EPWP, 2005). Exact figures presented in various policy documents differ, reflecting the evolution of the EPWP over time, and the more advanced state of programme development and implementation in some sectors relative to others. The 
figures discussed here are taken from the EPWP sector plans (EPWP, $2004 \mathrm{a}$,b, etc.), and should be regarded as indicative only. They suggest a total goal of 1.29 million cumulative work opportunities over the EPWP period.

[8] EPWP Social Sector Plan (2004a, p. 28).

[9] According to the EPWP Social Sector Strategy 'A learnership combines work-based experience with structured learning and results in a qualification that is registered within the National Qualifications Framework (NQF) by the South African Qualification Authority (SAQA). A learner who completes a learnership will have a qualification that signals occupational competence and which is recognised throughout the country. Each learnership consists of a specified number of credits and takes at least one year to complete. The learning may consist of a number of NQF aligned short courses, which make up the learnership curriculum. A learnership requires that a trainer, a coach, a mentor and an assessor assist the learner' (EPWP, 2004a, p. 4).

[10] These are contractors from previously disadvantaged racial groups.

[11] Elsewhere in the EPWP documentation a figure of 500, rather than 250 emerging contractors is cited as the target for CETA learnerships for the 5year period and in the Infrastructure Sector Plan for the Expanded Public Works Programme a figure of 180 in the first year. The difference between 500 and only 180 small contractors receiving learnership training is significant, inasmuch as it reduces the number of emerging SME contractors able to provide work opportunities for others. While there is debate about the real employment creation potential of SMEs, formal contractor learnership training has the potential multiplier effect of increasing unskilled employment - subject, of course, to growth in the construction industry. Notwithstanding this discrepancy, however, what is clear is that investment in training is to be focused exclusively on a small number of contractors rather than on the larger numbers of unskilled workers employed in the programme.

[12] Emerging civil contractors and individuals starting up in the construction industry are eligible for this training, which is conditional on municipal government having adequate capital to provide three training projects for the trainee contractor, for the purpose of practical training.

[13] This is not unexpected given the traditional 5-year duration of the artisanal training or apprenticeship in South Africa.

[14] INITIALS?? Marais (2003), personal communication.

[15] Early Childhood Development is the process by which children from birth to 9 years are nurtured to grow, and thrive physically, mentally, emotionally, spiritually, morally and socially. The focus on EPWP will be from birth to 6 years (EPWP, 2005).

[16] It is anticipated that up to 900,000 workers, representing approximately $70 \%$ of the total number of EPWP participants will work in the infrastructure sector, in which mean employment duration is 3-4 months. 
[17] 'Should this not be realised', the document continues, 'the projections of what can be achieved through this programme will be significantly affected'

[18] McCord draws on a large scale survey carried out in 2003 with workers from two public works programmes in Limpopo and KwaZulu Natal provinces, (the 'Gundo Lashu' and 'Zibambele' programmes, respectively), while Ndoto \& Macun draw on a qualitative study of three 'Working for Wetlands' projects in the Eastern Cape, Limpopo and Gauteng carried out in 2004.

[19] Narrow unemployment in rural Limpopo in 2003 was 38\% (Statistics South Africa, 2003).

[20] It is important to note the caveat McCord associates with these unemployment levels among former public works employees, that 'this finding implies poor labour market performance in the short to medium term, and that frictional unemployment may account for part of this high rate. The longer-term employment implications of PWP employment cannot be inferred from this study, as none of the former PWP employees interviewed had been unemployed for longer than 6 months. This finding indicates the importance of medium to long term tracking of the labour market performance of former PWP workers in order to assess their labour market impact in the long term'. For a more detailed discussion of these findings, see McCord (2004).

[21] See, for example, the Jua Kali programme in Kenya, focused exclusively on addressing practical constraints to increased informal sector activity (for an overview of this programme, see Ng'ethe \& Ndua, 1992).

[22] This is not a criticism of life-skills training, but rather a recognition that the objective of life skills training is not to promote labour market attachment.

[23] With the exception of the Social Sector plan, with its innovative promotion of para-social worker skills.

\section{References}

African National Congress (2005) Development and Underdevelopment: learning from experience to overcome the two-economy divide. African National Congress National General Council 2005 Discussion Document. Available at: www.anc.org.za/ancdocs/ngcouncils/2005/2economydivide.html

Ashton, D.N. (2004) High Skills: the concept and its application to South Africa, in S. McGrath, A. Badroodien, A. Kraak \& L. Unwin (Eds) The Shifting Understandings of 'Skill' in South Africa: overcoming the historical imprint. PUBLICATION DETAILS??

Bhorat, H. (2001) Employment Trends in South Africa, Occasional Paper no 2. TOWN?? Friedrich Ebert Stiftung, South Africa Office.

Bhorat H. (2004) Labour Market Challenges in the Post-Apartheid South Africa, South African Journal of Economics, 72, pp. 940-977. 
Bhorat, H. \& Hodge, J. (1999) Decomposing Shifts in Labour Demand in South Africa, South African Journal of Economics, 67, pp. 348-380.

Brunjes, B. (2003) The Future Ability of the Construction Sector to Execute Major Projects in South Africa: a construction industry perspective. TOWN?? Group Five Limited.

BuaNews (Pretoria) (2005) Government's Job Creation Programme on Track, BuaNews (Pretoria), 10 March 2005. Available at: http://allafrica.com/stories/200503100391.html.

Department of Public Works (2004) Presentation to EPWP Conference by Dr Sean Phillips, Director of the EPWP, Midrand, 25 February.

Devey, R. Skinner, C. \& Valodia, I. (2003) The Informal Economy, in: EDITORS?? Human Resources Development Directory. TOWN?? Human Sciences Research Council, South Africa.

EPWP (2004a) Social Sector Plan 2004/5-2008/9, Version 5, 24 February 2004. TOWN?? Departments of Social Development, Education and Health Social Sector Plan.

EPWP (2004b) Environment and Culture Sector Plan, 25 February 2004. TOWN?? EPWP, Department of Public Works.

EPWP (2005) Introduction to the Expanded Public Works Programme. Available at: http://www.epwp.gov.za

EPWP (undated) Infrastructure Sector Plan for the Expanded Public Works Programme. Available at: http://www.epwp.gov.za/downloads/sectors/ infrastructure/sectorplan.doc

Growth and Development Summit Development Agreement (2003) Pretoria: Department of Labour.

Kraak, A. (2003) HRD and the Skills Crisis, in: EDITORS?? Human Resources Development Directory. TOWN?? Human Sciences Research Council, South Africa.

Lee, D. \& Woolard, I. (2002) A Typology of the Unemployed: a policy of orientated approach, paper presented at the DPRTU/FES Conference on Labour Markets and Poverty in South Africa, Johannesburg, 22-24 October 2002.

Lewis J, (2001) Policies to Promote Growth and Employment in South Africa, discussion paper 16. Washington DC: Southern Africa Department World Bank, World Bank.

McCord, A. (2004) Policy Expectations and Programme Reality: the poverty reduction and employment performance of two public works programmes in South Africa, ESAU Working Paper. London: Overseas Development Institute. Available at: http://www.odi.org.uk/publications/working_papers/esau/

McCord, A. \& Bhorat, H. (2003) Employment and Labour Market Trends, in: EDITORS?? Human Resources Development Directory. TOWN?? Human Sciences Research Council, South Africa. NOT IN TEXT??

McCord, A. \& van Seventer, D.E. (2004) The Economy-wide Impacts of the Labour Intensification of Infrastructure Expenditure in South Africa, paper presented at the DPRU, TIPS \& Cornell Conference on African Development and Poverty 
Reduction, the Macro-Micro Linkages, Somerset West, South Africa, 13-15 October 2004

Meth, C. (2004) Half Measures: the ANC's unemployment and poverty reduction goals, DPRU Working Papers, No. 04/89, December 2004. Cape Town: University of Cape Town.

Nattrass. N. (2000) The Debate about Unemployment in the 1990s, Journal for Studies in Economics and Econometrics, 24, pp. 73-90.

Ndoto, M. \& Macun, I. (2005) World Wide Fund for Nature Rapid Socio-economic Survey of Working for Wetlands. Johannesburg: CASE, unpublished.

Ng'ethe N. \& Ndua, G. (1992) Jua Kali: education, training and welfare, a study of carpentry and metal-work in the Eastlands of Nairobi, Kenya, IDS Occasional Paper, Number 55. Nairobi: Institute for Development Studies, University of Nairobi.

Pollin, R., Epstein, G., Heintz, J. \& Ndikumana, L. (2005) An Employment-targeted Economic Program for South Africa, Draft Summary Document, unpublished, presented at University of Cape Town Seminar, South Africa, 11 March 2005. NOT IN TEXT??

Samson, M., Lee, U., MacQuene, K., van Niekerk, I. \& Gandhi, V. (2003) The Social and Economic Impact of Social Assistance Grants, Interim Report, commissioned by the Directorate, Finance and Economics, Department of Social Development, Pretoria, 31 August.

Statistics South Africa (2003) Labour Force Survey, March 2003, Statistical release P0210. Pretoria: Stat SA.

Statistics South Africa (2004) Labour Force Survey, March 2004, Statistical release P0210. Pretoria: Stat SA.

This Day (2003) Mbeki Promises a Million New Jobs, This Day, 12 November 2003. 